\title{
Recent advances in antiviral therapy
}

\author{
Derek Kinchington
}

\begin{abstract}
In the early 1980s many institutions in Britain were seriously considering whether there was a need for specialist departments of virology. The arrival of HIV changed that perception and since then virology and antiviral chemotherapy have become two very active areas of biomedical research. Cloning and sequencing have provided tools to identify viral enzymes and have brought the day of the "designer drug" nearer to reality. At the other end of the spectrum of drug discovery, huge numbers of compounds for screening can now be generated by combinatorial chemistry. The impetus to find drugs effective against HIV has also stimulated research into novel treatments for other virus infections including herpesvirus, respiratory infections, and hepatitis $B$ and $C$ viruses. The need to understand the function of the immune system during HIV infection has brought virologists and immunologists together into new partnerships. The huge increase in activity in antiviral research is reflected in the frequency with which these drugs are now being licensed: in 1985 there were two licensed antiviral drugs for systemic use. Since then approximately 20 compounds have been licensed and more are being submitted to the regulatory authorities on a regular basis.

(F Clin Pathol 1999;52:89-94)
\end{abstract}

Keywords: antiviral agents; viruses; immunology

Drugs for treating HIV infection

In 1985/86 the nucleoside analogue 3'-azido3'-deoxythymidine (AZT, or zidovudine, ZDV) was discovered as an inhibitor of the reverse transcriptase (RT) enzyme of HIV, ${ }^{1}$ the first of a line of antiviral agents used in the treatment of AIDS (table 1). This molecule blocks the formation of the RNA/DNA intermediate and prevents the double stranded proviral DNA from integrating into the host cell genome. The compound is given in an inactive form and is converted sequentially by cellular enzymes to the monophosphate, the diphosphate, and finally the bioactive triphosphate. Thus inactive zidovudine becomes the active zidovudine triphosphate on absorption, and is a substrate for reverse transcriptase. Incorporation of the phosphorylated form into the growing viral genome through 5'-3' ester linkages between adjacent sugars blocks any further chain elongation.

The early success achieved with zidovudine Dr Kinchington email:

d.kinchington@mds.qmw.ac.uk

Accepted for publication 3 November 1998 because of the development of drug resistance. ${ }^{4}$ Experience in the field of antimicrobials indicated that using a combination of drugs might overcome this problem. The only available drugs during the late 1980s were two other nucleotide reverse transcriptase inhibitors (NRTI) which also targeted HIV reverse transcriptase (HIV-RT): 2',3'-dideoxycytidine (ddC) and 2',3'-dideoxyinosine (ddI). ${ }^{56}$ In vitro combination studies gave surprising results: those viruses that became highly resistant to ZDV remained sensitive to both ddC and ddI. ${ }^{7}$ Furthermore, neither cross resistance nor interference between the drugs was an issue, and subsequent clinical experience showed that patients benefited when these two compounds were used in combination with ZDV. ${ }^{8}$ It was also found by in vitro studies that virus isolated from patients on long term $\mathrm{ZDV}$ monotherapy had become insensitive to ZDV, but regained sensitivity when these patients were switched to ddI monotherapy. Although the virus retained the ZDV resistance genotype, the mutation conferring resistance to ddI suppressed the ZDV resistance phenotype. ${ }^{7}$

A great improvement in nucleoside analogue combinations was the introduction of 3'thiaribofuranosyl-bL-cytosine (3TC or Epivar) into the regimens. This compound is a more potent inhibitor of HIV than either ddI or ddC, but when used as monotherapy 3TC selects for resistant strains very rapidly. However, studies of isolates from patients on ZDV/3TC combination treatment showed that the mutation in the reverse transcriptase gene conferring 3TC resistance also greatly delayed the generation of resistance to ZDV.

The use of cloned HIV-RT, in cell-free systems, as a target for anti-HIV drugs allowed the identification of a large number of nonnucleoside reverse transcriptase inhibitors (NNTRI) which selectively inhibited HIV-1 reverse transcriptase. These compounds were found to bind to reverse transcriptase in regions outside the nucleoside binding pocket. The first of these NNRTI were the TIBO derivatives, and the most potent compounds had a similar antiviral activity to ZDV. ${ }^{10}$ These compounds, although very potent, induced resistance after a few days of use and for a while interest was lost in their development. Their resurgence as useful drugs occurred once the principles of cross resistance between the various NRTI and the NNRTI were formulated at the molecular level. Two compounds, loviride and nevirapine, have been developed for clinical use $\mathrm{e}^{11} 12$ and these two classes of drugs, in combination with NRTI and proteinase inhibitors, have shown clinical efficacy. ${ }^{13}$

The third development, which extended the repertoire of drugs for anti-HIV treatment, was the discovery that HIV encoded an aspartyl protease. The synthesis of inhibitors against 
this enzyme quickly followed and saquinavir, the first of these protease inhibitors (PI), reached clinics in 1991. These are the most structurally complex of the compounds used in the treatment of HIV infections. ${ }^{14}$ Since then ritonavir and indinavir have also been licensed and nelfinavir and the new soft gel formulation, saquinavir-SGC, have undergone clinical trials $^{15-17}$ and are licensed.

The function of HIV proteinase is to cleave the large HIV gag-pol precursor protein into all the structural proteins of the virion and the virus specific enzymes. These proteins are protease itself (through an auto-enzymatic step), reverse transcriptase (incorporating RNAse $\mathrm{H})$, and integrase. The PI are polypeptide analogues of the natural substrates cleaved by HIV protease, and all these drugs have been optimised to bind with high affinity to the active site of the enzyme, thus blocking essential proteolytic steps needed for maturation of the virion. They are very potent

Table 1 Some approved drugs for treatment of HIV and other virus infections ${ }^{23}$

\begin{tabular}{|c|c|c|c|}
\hline Generic name & $\begin{array}{l}\text { Abbreviated and } \\
\text { Proprietary name }\end{array}$ & Principal activities & Description \\
\hline \multicolumn{4}{|c|}{ Nucleotide reverse transcriptase inhibitors (NRTI) } \\
\hline Didanosine & ddI Videx & HIV-1 and HIV-2 & $\begin{array}{l}\text { Purine NRTI used for the } \\
\text { treatment of advanced HIV disease } \\
\text { and in combination }\end{array}$ \\
\hline Lamivudine & 3TC Epivir & $\mathrm{HIV}-1, \mathrm{HIV}-2$, and HBV & $\begin{array}{l}\text { Pyrimidine NRTI used in } \\
\text { combination }\end{array}$ \\
\hline Stavudine & D4T Zerit & HIV-1 and HIV-2 & $\begin{array}{l}\text { Pyrimidine NRTI, used for adults } \\
\text { with advanced disease who are } \\
\text { intolerant to other approved } \\
\text { therapies or in combination }\end{array}$ \\
\hline Zalcitabine & ddC Hivid & HIV-1 and HIV-2 & $\begin{array}{l}\text { Pyrimidine NRTI, used for adults } \\
\text { with advanced disease who are } \\
\text { intolerant to ZDV treatment in } \\
\text { combination }\end{array}$ \\
\hline Zidovudine & AZT, ZDV Retrovir & HIV-1 and HIV-2 & $\begin{array}{l}\text { Pyrimidine NRTI, used for the } \\
\text { treatment of adults and children } \\
\text { with HIV disease }\end{array}$ \\
\hline \multicolumn{4}{|c|}{ Non-nucleotide reverse transcriptase inhibitors (NNRTI) } \\
\hline Delavirdine & U-90152S Rescriptor & HIV-1 & $\begin{array}{l}\text { Bis-heteroaryl-piperazine (BHAP) } \\
\text { derivative, in phase III trials }\end{array}$ \\
\hline Nevaripine & BI-RG 587 Viramune & HIV-1 & $\begin{array}{l}\text { Dipyridodiazepino NNRTI used in } \\
\text { combination with NTRI }\end{array}$ \\
\hline \multicolumn{4}{|c|}{ Proteinase inhibitors (PI) } \\
\hline Indinavir & MK-639 Crixivan & HIV-1 and HIV-2 & $\begin{array}{l}\text { Hydroxamino-pentene amide } \\
\text { derivative, used in combination } \\
\text { with NRTI or as monotherapy }\end{array}$ \\
\hline Nelfinavir & AG-1343 Viracept & HIV-1 and HIV-2 & $\begin{array}{l}\text { Non-peptide PI used, in } \\
\text { combination with NRTI or as } \\
\text { monotherapy }\end{array}$ \\
\hline Nitonavir & ABT-538 Norvir & HIV-1 and HIV-2 & $\begin{array}{l}\text { C2 symmetry-based PI, used in } \\
\text { combination with NRTI or as } \\
\text { monotherapy }\end{array}$ \\
\hline Saquinavir & R0 31-8959 Invirase & HIV-1 and HIV-2 & $\begin{array}{l}\text { Hydroxyethyl amine derivative } \\
\text { used in combination with NRTI }\end{array}$ \\
\hline $\begin{array}{l}\text { Soft gel formulation: } \\
\text { Saquinavir -SGC }\end{array}$ & Fortovase & & \\
\hline \multicolumn{4}{|c|}{ Some approved drugs for other viruses } \\
\hline Acyclovir & ACV Zovirax & $\begin{array}{l}\text { HSV-1, HSV-2, VZV, EBV and } \\
\text { CMV }\end{array}$ & $\begin{array}{l}\text { Purine nucleoside analogue, used } \\
\text { in the treatment of mucosal, } \\
\text { cutaneous and systemic HSV-1 and } \\
\text { HSV-2; also used for the } \\
\text { prophylaxis of HSV infections } \\
\text { (genital herpes), VZV and CMV } \\
\text { infections }\end{array}$ \\
\hline Famciclovir & FCV Famvir & $\begin{array}{l}\text { HSV-1, HSV-2, VZV, EBV and } \\
\text { HBV }\end{array}$ & $\begin{array}{l}\text { Acyclic guanine nucleoside (oral } \\
\text { prodrug of penciclovir); in phase } \\
\text { III clinical trials for HBV }\end{array}$ \\
\hline Foscarnet & PFA Foscavir & $\begin{array}{l}\text { HSV-1, HSV-2, CMV, VZV, EBV, } \\
\text { HHV-6, HIV and HBV }\end{array}$ & $\begin{array}{l}\text { Organic analogue of inorganic } \\
\text { pyrophosphate, used primarily in } \\
\text { the treatment of CMV disease }\end{array}$ \\
\hline Ganciclovir & GCV Cymevene/Cytovene & $\begin{array}{l}\text { HSV-1, HSV-2, CMV,HHV-6, } \\
\text { VZV, EBV and HBV }\end{array}$ & $\begin{array}{l}\text { Acyclic purine nucleoside used in } \\
\text { the treatment and prophylaxis of } \\
\text { CMV disease including CMV } \\
\text { retinitis }\end{array}$ \\
\hline Idoxuridine & $\begin{array}{l}\text { 5-IUdR Herpid, Stoxil, } \\
\text { Iduridin Virudox, } \\
\text { Idoxene, Kerecid }\end{array}$ & HSV-1, HSV-2 and VZV & $\begin{array}{l}\text { Iodinated analogue of thymidine, } \\
\text { used in the topical treatment of } \\
\text { keratoconjunctivitis caused by } \\
\text { HSV and cutaneous herpes zoster }\end{array}$ \\
\hline Ribavirin & $\begin{array}{l}\text { ICN-1229 Virazid, } \\
\text { Virazide, Virazole, Vilona }\end{array}$ & $\begin{array}{l}\text { RSV, MV, HAV, HBV, HCV, } \\
\text { influenza A and B, Lassa viruses, } \\
\text { Hantaan and Junin virus }\end{array}$ & $\begin{array}{l}\text { Nucleoside analogue used } \\
\text { primarily in the treatment of RSV } \\
\text { in infants; useful wide spectrum } \\
\text { antiviral in life threatening } \\
\text { situations }\end{array}$ \\
\hline Valaciclovir & VACV Valtrex & $\begin{array}{l}\text { HSV-1, HSV-2, VZV, EBV and } \\
\text { CMV }\end{array}$ & $\begin{array}{l}\text { Acyclic guanine nucleoside (oral } \\
\text { prodrug of acyclovir) }\end{array}$ \\
\hline Zanamir & Relenza & influenza $A$ and $B$ viruses & $\begin{array}{l}\text { Sialic acid analogue, } \\
\text { neuraminidase inhibitor }\end{array}$ \\
\hline
\end{tabular}


inhibitors of HIV and can have a have a significant impact on HIV replication for several months when used as a monotherapy. However, with time treatment failure still occurs in most patients, again caused by the selection of mutant strains of HIV and the subsequent development of resistance.

CHANGING THE PARADIGM

In 1995 two reports were published which reversed what was once the conventional view that HIV was present in small quantities in infected individuals. ${ }^{18} 19$ This change in our understanding of the kinetics of HIV replication followed exploration of the potent antiviral effect of the proteinase inhibitors, and the new PCR technology which enabled very sensitive changes in HIV replication to be measured as the viral load (HIV RNA copy number $/ \mathrm{ml}$ of blood). ${ }^{20}$ Studies measuring the drop in viral load in patients treated with ritonavir and indinavir monotherapies showed that $10^{9}-10^{10}$ virus particles are produced and cleared daily in peripheral blood. ${ }^{18}$ Further, at the end of the acute phase of infection each individual achieved a steady viral load concentration which ranged from $10^{2}-10^{6}$ copies $/ \mathrm{ml}$ of blood. This was in contrast to an earlier model of HIV infection, which proposed a relatively low steady state of HIV replication, based on less sensitive measurements of viral concentration.

The original assumption made about antiHIV treatment was that drugs could inhibit the production of new virus but could not quickly eliminate virus already present in the blood stream. Treatment of infected individuals with protease inhibitors showed very dramatically that every two days the level of plasma HIV was reduced by half and that within 14 days viral load could be reduced by $2-3$ logs. The conclusion drawn from these studies was that chronically infected cells, which are a small proportion of the total number of peripheral blood mononuclear cells, are not capable of replenishing daily plasma HIV levels. For plasma HIV levels to reach those observed in untreated individuals many new cells of the immune system need to be infected constantly. It was estimated that about $5 \%$ of the daily production of CD4+ cells, the primary host cell for HIV replication, are killed by HIV. ${ }^{21}$ Further studies showed that a turnover of 10-100 million CD4+ cells per day was usual in infected people not undergoing chemotherapy. Studies on CD4+ kinetics with the protease inhibitors showed that the rise in CD4+ counts doubled every 15 days and correlated with a fall in viral load. Further, the data showed that even in severely immunocompromised people a significant increase in CD4+ count occurred.

More recently it has been proposed that the large increase in CD4+ found in peripheral blood following effective antiretroviral treatment is not primarily the result of $\mathrm{T}$ cell proliferation but is caused by a redistribution of the cells already present. During active viral replication masses of $\mathrm{T}$ and $\mathrm{B}$ cells are trapped in the lymph nodes by the immune response and can remain in there for a long time. Following chemotherapy, it is the release of these cells into the blood that causes a rise in $\mathrm{T}$ cells rather than a high level of proliferation. ${ }^{22}{ }^{23}$ These studies on HIV dynamics have indicated that that lymph nodes of the secondary lymphoid system are the major reservoir of HIV and not the circulating PBMC. It has been proposed that long memory $\mathrm{T}$ cells constitute a major compartment in which HIV survives. ${ }^{24}$ It is on the latently infected long lived compartments within the body that antiretroviral treatment must have its impact if HIV is to be eliminated.

This new understanding of HIV kinetics has several consequences for HIV treatment. Virus replication, as measured by the HIV RNA levels, is clearly related to clinical progression. ${ }^{25}$ Thus driving down the viral load as far as possible has become a goal of antiretroviral treatment. Further, it is considered that the rapid development of drug resistance results from the very high replication rate of HIV and not from an abnormally high mutation rate. Clinical trial data show that long term suppression of HIV replication can only be achieved by the use of several drugs in combination, and this approach is now used as first line treatment. However, the efficacy of the combination is dependent on the cross resistance profiles of each drug and not necessarily on the potency of the drug. The use of one PI in combination with two NRTI is now considered to be one of the most potent anti-HIV regimens to date (HAART, highly active antiretroviral treatment). Consensus opinion is that the most potent combination antiretroviral treatment should begin as soon as possible and certainly once the virus load begins to increase. ${ }^{26}$

If treatment can reduce HIV replication to very low levels there is hope that the compartments harbouring infected cells may be cleared by the immune system itself. Even though some patients achieve large increases in CD4+ counts with antiretroviral treatment their ability to mount an immune challenge is still suboptimal. A further approach to HIV chemotherapy now receiving much attention is to combine antiretroviral treatment with an immunomodulator. The most studied treatment is with interleukin 2 (IL-2). Individuals treated with IL-2 have sustained a significant improvement in their CD4+ counts compared with people who have received antiretroviral treatment alone. In some cases CD4+ counts have risen by $400 / \mu 1 .^{27}$ There are also data suggesting that individuals who start treatment with a higher CD4+ count have the best response. Thus, theoretically, immunomodulators should be used sooner rather than later in the infection. IL-2 itself is toxic and requires infusion over a period of time. It also enhances HIV replication, but this is controlled by concomitant antiretroviral treatment. Recently several other biological response modifiers, cytokines, and small molecular weight molecules have been investigated in HIV infections. ${ }^{28-31}$ 


\section{Drugs for herpesvirus infections}

Acyclovir was discovered in the 1974 and was the first effective antiviral drug to be used extensively. ${ }^{32}$ It is a guanine analogue with a truncated sugar and is a member of the class of acyclic nucleotide inhibitors. This compound is widely used for the treatment of herpesvirus-1 (HSV-1) and HSV-2 infections. It is the safest of all the nucleoside analogues as it requires the virus to activate the compound. The first phosphorylation step is carried out by the virus enzyme, thymidine kinase, a process which is about 200 times faster than the host cell analogue. ${ }^{33}$ The pharmacological result of this selectivity is that ACV is essentially absent in uninfected cells. The second and third phosphorylation steps are brought about by cellular enzymes. ACV-triphosphate competes with the normal substrate, deoxyguanosine triphosphate, for the herpesvirus DNA polymerase, and incorporation of ACV-triphosphate into the growing virus DNA causes chain termination. Advances have been made recently in synthesising valaciclovir (VCV) which is the prodrug of ACV. ${ }^{34} \mathrm{VCV}$ has a half life of about 12 hours and is consequently given less often, which improves compliance. Famciclovir (FCV), ${ }^{35}$ a prodrug of penciclovir (PCV),${ }^{36}$ has also been licensed for the treatment of varicella-zoster virus and genital herpes. It has a similar mode of action to acyclovir, but PCV-triphosphate has a half life about 20 times longer than ACV-triphosphate, although being a significantly weaker inhibitor of herpesvirus DNA polymerase.

The development of resistance to ACV is not an important issue in the treatment of herpesvirus infections in non-immunocompromised hosts because acyclovir resistant strains are less fit and do not outgrow the wild type. In immunocompromised patients, however, they may be a serious cause of morbidity, and foscarnet may be given if ACV treatment is unsuccessful. ${ }^{37}$ The most life threatening virus in immunosuppressed patients is cytomegalovirus (CMV), and another nucleoside analogue, ganciclovir (GCV), was developed to treat CMV reactivation in HIV infected patients and those undergoing transplantation. The viral target is the CMV DNA polymerase. ${ }^{38}$ Biochemical studies have shown that GCV, like ACV, is phosphorylated by a viral protein, in this case the UL97 viral gene product. The amino acid sequence of this UL97 indicates that it is primarily a protein kinase, but it also possesses the ability to phosphorylate nucleosides. ${ }^{39}$ More recently HPMPC (cidofovir), a nucleoside monophosphate, has been developed to treat CMV retinitis in AIDS patients. Again the target is the CMV DNA polymerase. The drug causes severe renal toxicity, but because it is stable for many days it can be delivered directly to the eye intermittently, thus avoiding systemic overexposure. ${ }^{40}$ Molecular cloning of the herpesviruses has also revealed a conserved sequence coding for a protease which is an essential gene function for their replication. Although this enzyme is well characterised and high throughput assays systems have been developed, there has been no major breakthrough in the discovery of potent inhibitors to date.

\section{Influenza infections}

Many other viral infections cause significant human disease, but until recently antiviral intervention has not achieved much success. Influenza epidemics are common and account for many fatalities, particularly in infants and elderly people.

Amantadine and rimatadine are compounds which were found to block an ion channel established by influenza $\mathrm{A}$ in order to allow the virion to fuse with the cell membrane and enter the cell. However, drug resistance occurs within a few rounds of replication, which proved to be a serious limitation to their use. The most recent advance in this field is the development of influenza neuraminidase inhibitors. Neuraminidase is a glycoprotein found in the viral envelope, and involved in the cell to cell spread of the virus. Neuraminidase is active at a late stage in influenza replication and removes cellular receptors which bind the other major influenza surface enzyme glycoprotein, haemagglutinin, a process essential for virus-cell fusion. Thus interference with neuraminidase activity inhibits the escape of the influenza virus from the infected cell. Crystallographic studies have shown that the active site of neuraminidase is highly conserved in all strains of influenza A and B, thus supporting its role as a target for chemotherapy. A number of potent inhibitors of both influenza $\mathrm{A}$ and $\mathrm{B}$ neuraminidase have been synthesised: zanamivir (4-guanidino-2,4dideoxy-2,3-dehydro-N-acetylneuraminic acid) ${ }^{41}$ and GS4104, ${ }^{42}$ which is a neuraminidase inhibitor prodrug, are the first to have significant activity in vivo. Zanamivir is given by aerosol as it is cleared rapidly from the plasma when given systematically. Recent trials have shown that, when taken prophylactically or within 26 hours after infection, zanamivir is effective in reducing symptoms. Resistance does occur but the neuraminidase of the viral mutants is unstable and such viruses do not replicate as well as the wild type.

\section{Hepatitis virus infections}

Chronic viral hepatitis is known to infect several hundred million people worldwide and causes severe liver disease. The association of hepatitis B and C viruses with blood transfusion, intravenous drug use, and sexual exposure has encouraged the pharmaceutical industry to expand their drug discovery programmes in this area.

The acute disease seen in hepatitis $B$ virus (HBV) infection ranges in severity from asymptomatic to fatal fulminant hepatitis. The chronic condition also varies from benign conditions to chronic active hepatitis and liver cancer. The World Health Organisation estimates that of the 350 million carriers of HBV, 65 million will die of chronic liver disease. Studies have determined that HBV has a virally encoded reverse transcriptase which transcribes viral RNA into DNA, within the core particles, during the late stages of the replication cycle. Thus many of the reverse transcriptase inhibitors which showed activity against HIV were evaluated against HBV. 
Unfortunately most of the compounds which were active in vitro were found to be either inactive or too toxic in vivo. However, a few drugs are under development. The antiherpes prodrug, famciclovir, is in phase II clinical studies and suppresses the virus load in chronic $\mathrm{HBV}$ infection. Originally it was thought that famciclovir required activation by the herpes specific thymidine kinase but it is now clear that cellular kinases can carry out the first phosphorylation step. ${ }^{43}$ Treatment with lamivudine, which is in phase III development, resulted in significant histological improvement in most patients as well as a statistically significant reduction in $\mathrm{HBV} e$ antigen (HBeAg) seroconversion. These compounds do not clear the infection and a "rebound effect" is observed in HBV replication when treatment is withdrawn. ${ }^{44}$ Both famciclovir and lamivudine induce mutations in the HBV RNA polymerase, and although the HBV mutation rate is similar to that of the retroviral pol gene the emergence of resistance takes much longer than for HIV. The virulence and replication capacity of these drug resistance strains has yet to be assessed in relation to the pathogenesis of HBV.

The nucleoside analogue, BMS-200475, a cyclopentyl guanosine analogue, is in phase I/II development. In the WHV (woodchuck hepatitis virus) model there are data indicating that this compound may be one of the most potent HBV inhibitors under development; phase I studies indicate that total daily doses as low as $5 \mathrm{mg}$ may be effective. ${ }^{45}$ The acyclic nucleoside analogues adefovir dipivoxil and lobucavir are also in phase II development; both induce approximately a $2 \log$ drop in HBV DNA over several months of treatment.

Hepatitis $\mathrm{C}$ virus (HCV) was first identified in 1989 as the non-A non-B transfusion associated virus by a combination of cDNA cloning and expression techniques. Subsequent DNA sequence analysis showed it to be a member of the flavivirus group. Worldwide prevalence is estimated to be 300 million chronically infected carriers. The severe consequences of long term infection and the limitations of interferon alfa as treatment have stimulated the research efforts aimed at identifying novel antiviral agents against this virus. This has proven to be a more difficult problem than with HBV as $\mathrm{HCV}$ cannot as yet be grown in tissue culture.

The success of the protease inhibitors against HIV have stimulated the search for compounds that inhibit the serine protease activity which is located at the N-terminal end of the HCV NS3 protein. This viral enzyme is needed for post-translational processing of the non-structural region of the $\mathrm{HCV}$ polyprotein. ${ }^{46}$ Even though high throughput screens - using cell-free systems - are in place, no potent inhibitors have been reported. However, modest antiviral activity against the isolated protease has been achieved with substrate based peptide mimetics. Polyprotein inhibitors selected from bacteriophage libraries have also shown some activity.
The other key target is the HCV helicase which is located at the $\mathrm{C}$ terminal end of the NS3 protein. This is essential for RNA replication and presents various potential sites for small molecule inhibitor binding. These include the binding sites for ATP, the single stranded polynucleotide, and the double stranded polynucleotide, all of which may exist in multiple conformations. A molecule which traps the enzyme in either an open or a closed conformation would also block its activity. Current treatment for $\mathrm{HCV}$ infections is with interferon alfa, but only about one third of patients respond and the symptoms return following cessation of treatment. Ribavirin has been used for the treatment of $\mathrm{HCV}$ and although there seems to be no effect on the level of circulating virus there may be a reduction in the markers of active hepatitis. ${ }^{47}$

\section{Human papilloma virus infections}

The other main group of viruses under investigation are the human papilloma viruses (HPV), in particular the mucosal types associated with benign and premalignant lesions and cervical cancer. Epidemiological studies have clearly established a link between high grade precancerous disease and the two genotypes HPV-16 and HPV-18. Treatment is varied and includes surgical intervention, cryotherapy, and laser vaporisation. 5-Fluorouracil (5FU), an anticancer agent, and podophyllin, an antimitotic agent, have been used as topical agents. However, these treatments often do not eliminate the HPV DNA and recurrent disease develops, usually around the previously treated area. The most promising treatment for HPV infections is systemic interferon alfa, where clear benefit has been observed in double blind placebo controlled trials.

In the next few years, antiviral chemotherapy is still most likely to be concerned with the search for compounds that can accurately target viral enzymes. The identification and cloning of viral genes is now routine because of PCR technology, even when there is no cell system for growing the virus itself. Ultimately, successful control and perhaps eradication of virus infections will depend on increased expertise in manipulating the immune system, together with antiviral drugs. The consolidation of this field of study is important. New viral infections are now common throughout the world; some are predictable but others, like HIV, may suddenly emerge. These may be controlled if the appropriate scientific infrastructure is in place.

I thank Dr John Williamson for his comments on this review.

1 Mitsuya H, Weinhold KJ, Furman PA, et al. 3-Azido-3deoxythymidine: BW A509U; an antiviral agent that inhibits the infectivity and cytopathic effect of human T-lymphotrophic virus type III/lymphadenopathy associated virus in vitro. Proc Natl Acad Sci USA 1985;82:7096100 .

2 Balzarini J, Schinazi RF, D Kinchington. Factfile of current antiviral agents, 3rd edition. Part I. Herpesviruses and other viruses. International Antiviral News 1997;5:74-81.

3 Kinchington D, Balzarini J, Field HJ. Factfile of current Kinchington D, Balzarini J, Field H. Factfile of current
antiviral agents, 3rd edition. Part II. Human immunodefiantiviral agents, 3rd edition. Part II. Human immunodefi-
ciency viruses. International Antiviral News 1997;5:161-74. 4 Larder BA, Kemp SD. Multiple mutations in HIV-1 transcriptase confer high level resistance to zidovudine (AZT). Science 1989;246:1155-8. 
5 Mitsuya H, Broder S. Inhibition of the in vitro infectivity and cytopathic effect of human T-lymphotrophic virus type 2,3-dideoxynucleosides. Proc Natl Acad Sci USA 1986;83: 2,3-dideoxy

6 Delta Co-ordinating Committee. Delta: a randomised double blind controlled trial comparing combinations of zidovudine plus didanosine or zalcitabine with zidovudine alone in HIV-infected individuals. Lancet 1996;348:283-91.

7 St Clair MH, Martin JL, Tudor-Williams G, et al. Resistance to ddI and sensitivity to AZT induced by a mutation in HIV-1 reverse transcriptase. Science 1991:253: 1557-9.

8 Hammer SM, Katzenstein DA, Hughes MD, et al. A trial comparing nucleoside monotherapy with combination therapy in HIV-1 infected adults with CD4 cell counts from 200-500/microlitre (ACTGS 175). N Engl $\mathcal{F} \mathrm{Med}$ 1996; 335: 1081-90.

9 Tisdale M, Kemp, Parry NR, et al. Rapid in vitro selection of human immunodeficiency virus type 1 resistant to of human immunodeficiency virus type 1 resistant to 3-thiacytidine inhibitors due to a mutation in the YMDD region of reverse

10 Pauwels R, Andries K, Debyser Z, et al. Potent and selective HIV-1 inhibition by a series of alphaanilinophenylacetamide derivatives targeted at HIV-1 reverse transcriptase. Proc Natl Acad Sci USA 1993;90 1711-15

11 Merluzzi VJ, Hargrave KD, Labadia M, et al. Inhibition of HIV-1 replication by a non-nucleoside reverse transcriptase inhibitor. Science 1990;250:1411-13.

12 Staszewski S, Miller V, Rehmet S, et al. Virological and Immunological analysis of a triple combination pilot study with loviride, lamivudine and zidovudine in HIV-1 infected patients. AIDS 1996;10: $\mathrm{F} 1-7$.

13 D'Aquila RT, Hughes MD, Johnson VA, et al, Institute of Allergy and Infectious Diseases AIDS Clinical Trials Group. Nevirapine, zidovudine and didanosine compared with zidovudine and didanosine in patients with HIV-1 with zidovudine and didanosine in patients with HIV-1 infection. A randomised, double blind, p

14 Roberts NA, Martin J, Kinchington D, et al. Rational design of peptide based HIV proteinase inhibition. Science 1990;248:358-61.

15 Danner SA, Carr A, Leonard JM, et al. A short term study of the safety, pharmacokinetics and efficacy of ritonavir, an inhibitor of HIV-1 protease. N Engl F Med 1995;333:152833.

16 Stein DS Fish DG, Bilello JA, et al. A 24 week open-label phase I/II evaluation of the HIV protease inhibitor MK-639 (indinavir). AIDS 1996;10:485-92.

17 Shetty BV, Kosa MB, Khalil DA, et al. Preclinical pharmacokinetics and distribution to tissue of AG1343, an inhibitor of human immunodeficiency virus type 1 protease. Antimicrob Agents Chemother 1996;40:110-14.

Antimicrob Agents Chemother 1996;40:110-14.
18 Ho DD, Neumann AU, Perelson AS, et al. Rapid turnover of plasma virions and CD4 lymphocytes in HIV-1 infection. Nature 1995;373:123-6.

19 Wei X, Ghosh SK, Taylor ME, et al. Viral dynamics in human immunodeficiency virus type 1 infection. Nature human immunod

20 O'Brien WA, Hartigan PM, Martin D, et al. Changes in plasma HIV-1 RNA and CD4+ lymphocyte counts and the risk of progression to AIDS. N Engl F Med 1996;334:42631.

21 Perelson AS, Neumann PM, Martin D, et al. HIV-1 dynamics in vivo: virion clearance rate, infected cell life-span and viral generation time. Science 1996;271:1582-6.

22 Pakker NG, Notermans RJ, De Boer MTL, et al. Biphasic kinetics of peripheral blood T-cells after triple combination therapy in HIV infection: a composite redistribution and proliferation. Nature Med 1988;4:208-15.

23 Gorochov G, Neumann A, Kereveur A, et al. Perturbation of $\mathrm{CD} 4+$ and $\mathrm{CD} 8+\mathrm{T}$ cell repertoires during progression to AIDS and regulation of the CD4+ repertoire during antiviral therapy. Nature Med 1998;4:215-21.

24 Perelson AS, Essunger P, Cao Y, et al. Decay characteristics of HIV-1-infected compartments during combination of HIV-1-infected compartment

25 Mellors JW, Kingsley LA, Rinaldo CR, et al. Quantification of HIV-1 RNA in plasma predicts outcome after seroconversion. Ann Intern Med 1995;122:573-9.
26 Carpenter CC, Fischl MA, Hammer SM, et al. Antiretroviral therapy for HIV infection in 1997. Updated recommendations of the International AIDS Society-USA panel. FAMA 1997;277:1962-9.

27 Kovacs JA, Vogels, Albert JM, et al. Controlled trial of interleukin-2 infusions in patients infected with the human immunodeficiency virus. N Engl f Med 1996;335:1350-6.

28 Gottlieb AA, Gottleib MS. Development of immunomodulators for treatment of HIV infection. Lymphology 1990;23: $98-101$.

29 Touraine JL, Sanhadji K, Zerhouni B, et al. Rationale for a combined use of antiretroviral and immunomodulatory therapies in HIV infection. Int $\mathcal{f}$ Immunopharmacol 1991;13(suppl 1):43-8.

30 Rhodes J, Hen H, Hall SR, et al. Therapeutic potentiation of the immune system by costimulatory Schiff-base-forming drugs. Nature 1995;377:71-5.

31 Kinchington D, Ng T, Mathews N, et al. T-cell costimulation by a derivative of benzoic acid. Antiviral Chem Chemother 1997;8:121-30.

32 Wagstaff AJ, Faulds D, Goa KL. Acyclovir. A reappraisal of its antiviral activity, pharmacokinetic properties and therapeutic efficacy. Drugs 1994;47:153-205.

33 Darby G. The acyclovir legacy: its contribution to antiviral drug discovery. $\mathcal{F}$ Med Virol 1993;suppl 1:134-8.

34 Beutner KR, Friedman DJ, Forszpaniak C, et al. Valaciclovir compared with acyclovir for improved therapy for herpeszoster infections in immunocompetent adults. Agents Chemother 1995;39:1546-53.

35 Perry CM, Wagstaff AJ. Famciclovir-a review of its pharmacological properties and therapeutic efficacy in herpesvirus infections. Drugs 1995;50:396-415.

36 Vere-Hodge RA, Sutton D, Boyd MR, et al. The mode of action of penciclovir. Antiviral Chem Chemother 1993;4:1324

37 Wagstaff AJ, Bryson HM. Foscarnet: a reappraisal of its antiviral activity, pharmacokinetic properties and therapeutic use in immunocompromised patients with viral infections. Drugs 1994;47:153-205.

38 Spector SA, McKinley GS, Lalezari JP, et al. Oral ganciclovir for the prevention of cytomegalovirus disease in persons with AIDS. N Engl f Med 1996;334:1491-7.

39 Littler E, Stuart AD, Chee MS. Human cytomegalovirus UL97 open reading frame encodes a protein that phosphorylates the antiviral nucleoside analogue ganciclovir. Nature 1992;358:160-2.

40 Bischofberger N, Hitchcock MJM, Chen MS, et al. 1-[(S)-2-Hydroxy-2-oxo-1,4,2-dioxaphosphoranin-5yl)methyl] cytosine with improved therapeutic index in vivo. Antimicrob Agents Chemother 1994;38:2387-91.

41 Hayden FG, Treanor JJ, Betts RF, et al. Safety and efficacy of the neuraminidase inhibitor GG167 in experimental human influenza. FAMA 1996;275:295-9.

42 Kim CU, Williams MA, Liu H, et al. Influenza neuraminidase inhibitors possessing a novel hydrophobic interaction in the enzyme active site: design synthesis and structural analysis of carbocyclic sialic acid analogues with potent anti influenza activity. $\mathcal{F}$ Am Chem Soc 1997;119:681-90.

43 Shaw T, Mok SS, Locarnini SA. Inhibition of hepatitis B virus DNA polymerase by enantiomers of penciclovir triphosphate and metabolic basis for selective inhibition of HBV replication by penciclovir. Hepatology 1996;24:9961002.

44 Main J, Brown JL, Howells SA, et al. A double blind, placebo controlled study to assess the effect of famciclovir on virus replication in patients with chronic hepatitis B virus infection. $\mathcal{I}$ Viral Hepatitis 1996;3:211-15.

45 Innaimo SF, Seifer M, Bisacchi GS, et al. Identification of BMS-200475 as a potent and selective inhibitor of hepatitis B virus. Antimicrob Agents Chemother 1997;41:1444-8.

46 Bartenschlager R, Lohmann V, Wilkinson T, et al. Complex formation between the NS3 serine type proteinase of the hepatitis C virus and NS4A and its importance for polyprotein maturation. F Virol 1995;69:7519-28.

47 Bodeinheimer HC, Lindsay KL, Davis G, et al. Tolerance and efficacy of oral ribavirin treatment of chronic hepatitis C: a multicentre trial. Hepatology 1997;26:473-7. 